\title{
Biodiversity-ecosystem functioning relationships of overstorey versus understorey trees in an old-growth temperate forest
}

\author{
Wei Xu ${ }^{1} \cdot$ Weixue Luo ${ }^{1} \cdot$ Chunyu Zhang ${ }^{1} \cdot$ Xiuhai Zhao $^{1}$ (D) $\cdot$ Klaus von Gadow $^{2,3} \cdot$ Zhonghui Zhang $^{4}$
}

Received: 14 May 2018 / Accepted: 6 May 2019 / Published online: 21 June 2019

(C) INRA and Springer-Verlag France SAS, part of Springer Nature 2019

\begin{abstract}
- Key message The results of this study, based on a large dataset with mapped tree locations, suggest that the relationship between biodiversity and ecosystem functioning (BEF) is different between the over- and understorey in the investigated forest community. Neither the functional nor the phylogenetic diversity showed a significant advantage in predicting aboveground biomass and biomass production (aboveground biomass increment) when compared with species richness. - Context Consistent conclusions have still not been reached regarding the relative importance of the different diversity indices in predicting biomass production. Furthermore, the effects of certain forest strata on the BEF relationship remain unclear.

-Methods The woody plant species in the study area were classified as two vertical strata and were referred to as the "overstorey" (trees with $\mathrm{dbh}>10 \mathrm{~cm}$ ) and "understorey" (trees with $\mathrm{dbh} \leq 10 \mathrm{~cm}$ ). The relationships between different metrics of tree diversity and biomass production were quantified using linear models. The set of the best predictors for tree biomass and productions were determined using a multi-model selection approach. The differences in diversity-ecosystem functioning relationships between the two forest vertical strata, and the effects of canopy trees on the understorey trees, were investigated using structural equation models.

- Aims The relative importance of the species diversity, phylogenetic diversity, and functional diversity in predicting the aboveground biomass production (ABP) was examined to compare the potential of phylogenetic and functional diversity indices and species richness in predicting biomass productivity and compare the influence of niche complementarity, selection effects, or mass-ratio effects on aboveground biomass variables and to assess possible differences in the BEF relationships between the overstorey and understorey layers in the studied ecosystems. Also, this study investigated possible differences in the BEF relationships between the overstorey and understorey layers in the studied ecosystems.

- Results The results confirmed a positive diversity-productivity relationship in the natural coniferous and broadleaved mixed forest. However, the relationship in the overstorey stratum was statistically stronger than that in the understorey layer. The combination of diversity indices and functional traits could explain more of the variations in the biomass and productivity than when examined separately. The correlation between the richness of the overstorey and understorey species was found to be positive. However, the aboveground woody biomass of the overstorey layer had negative effects on the understorey biomass.
\end{abstract}

Handling Editor: Laurent Bergès

Contribution of the co-authors WX analyzed the data and wrote the manuscript; $\mathrm{WL}, \mathrm{CZ}, \mathrm{KvG}$, and $\mathrm{ZZ}$ modeled and interpreted the results; $\mathrm{XZ}$ performed project coordination and research concept.

Electronic supplementary material The online version of this article (https://doi.org/10.1007/s13595-019-0845-8) contains supplementary material, which is available to authorized users.

Xiuhai Zhao

bfuz@163.com

1 Research Center of Forest Management Engineering of State Forestry and Grassland Administration, Beijing Forestry University, No.35 Qinghua East Road, Haidian District, Beijing 100083, People's Republic of China
2 Faculty of Forestry and Forest Ecology, Georg-August-University Göttingen, Büsgenweg 5, D-37077 Göttingen, Germany

3 Department of Forest and Wood Science, University of Stellenbosch, Stellenbosch 7600, South Africa

4 Jilin Province Academy of Forestry Sciences, Jilin, China 
- Conclusion In summary, this study found a stronger positive correlation between the woody plant diversity and productivity in the overstorey than in the understorey stratum. These findings indicate that the BEF relationships are hierarchically dependent, and supported by niche complementarity. Also, a much weaker relationship was observed between the functional diversity and biomass production than between the species diversity and biomass production due to a selection effect. The aboveground woody biomass was found to be enhanced in communities dominated by functional traits correlated to smaller leaf areas, greater maximum tree heights, and higher leaf carbon content. These findings suggest that the BEF relationships were driven by a mass-ratio hypothesis.

Keywords Temperate forest $\cdot$ Temperate forest $\cdot$ Tree species diversity $\cdot$ Biomass productivity $\cdot$ Vertical forest stratum

\section{Introduction}

The biodiversity and ecosystem functioning relationships are known to be positive in natural forests, which suggests that a greater species richness in a particular community tends to facilitate fuller resource usage and greater productivity (Cardinale et al. 2006; Liang et al. 2016; Liu et al. 2016; Wang et al. 2016; Webb and Donoghue 2005; Zhang et al. 2012). However, most of the previous studies have focused on species richness, which only partly accounts for the productivity of communities, and cannot fully explain certain differences or similarities between species (Cardinale et al. 2006). Furthermore, many studies have explored the biodiversity and ecosystem functioning relationships by using measurements of the functional and phylogenetic diversities as predictors of the ecosystem functions (EFs) (Cadotte 2015; Lei et al. 2016; Venail et al. 2015).

The exploration of the relative importance of the different diversity indices in predicting productivity has become an important research issue. Previously, researchers were not successful in obtaining consistent conclusions (Cadotte 2015; Cadotte et al. 2009; Cadotte et al. 2010; Liu et al. 2015; Liu et al. 2016; Yuan et al. 2016). It was found that the phylogenetic diversity explained more of the variables of the plant biomass accumulation when compared with the taxonomy diversity and functional group richness (Cadotte et al. 2008). However, Venail et al. (2015) found that phylogenetic diversity was not a better explanatory variable than species richness in predicting the community biomass in 16 grassland experiments. In a removal experiment using natural alpine assemblages in the Tibetan Plateau, Liu et al. (2015) found that multivariate functional diversity indices alone consistently explained more of the variations in productivity than other single measures (phylogenetic, richness, and evenness). Studies conducted by Yuan et al. (2016) revealed that the relationships between biomass and phylogenetic diversity variables were more often significantly positive than the relationships between biomass variables and species richness and/or functional dispersion in broad-leaved Korean pine forests. These findings suggest that further research is required regarding the relationship between phylogenetic and functional diversities and ecosystem functions.
The relative contributions of the different measures of biodiversity in promoting ecosystem functions should indicate which hypothesis could be used to explain the biodiversity and ecosystem functioning relationships in the study area. A positive correlation was found between the aboveground woody biomass (AWB) and functional diversity by Zhang et al. (2012) who believed that this may have resulted from niche complementarity, in which a higher diversity of species occupying more niche allowed each species to make full use of the limited resources in order to increase its individual contribution to ecosystem functioning (Loreau 2000). Selection effects may also explain such a positive relationship between AWB and diversity (Fox 2005), as forests with higher biodiversity are more likely to be characterized by high productivity of ecologically important species. Based on the selection effects hypothesis, Fotis et al. (2018) could show that the relationship between the functional diversity and AWB would be much weaker than the relationship between the taxonomic diversity and the AWB. Thus, a mass-ratio hypothesis, where ecosystem functions are driven by the traits of the most dominant species in the community, could be used to predict ecosystem functions at given points in time; this is chiefly determined by the trait values of the dominant contributors to total plant biomass (Grime 1998). According to the mass-ratio hypothesis, the EFs should be predictable from the community-weighted mean (CWM) trait values, with proven links to the different resource captures, usages, and releases at the ecosystem level and the level of the individual (Díaz et al. 2007).

In the past, the development of biodiversity and ecosystem functioning relationships in forest ecosystems has been focusing mainly on the canopy trees while the understorey trees, shrubs, and herbaceous plants were ignored (Zhang et al. 2016). The failure to consider all components of the vegetation may have generated misleading conclusions (Fowler et al. 2012), as well as divergent results regarding the relationships between biodiversity and the functioning of ecosystems (Balvanera et al. 2013). Therefore, forest structure and the vertical forest strata should not be ignored. The canopy species play a leading role in assessing the overall productivity of a forest. However, the understorey plants also contribute 
significantly to the nutrient cycling and soil carbon accumulation processes (Gilliam 2007; Nilsson and Wardle 2005; Zhang et al. 2016). Zhang et al. (2017) found stronger positive relationships between the species diversity and biomass production in the overstorey layer than in the understorey layer, where the understorey tree species richness was positively affected by the overstorey species. Ali and Yan (2017) found a forest strata-dependent relationship between the biodiversity and the aboveground biomass. Li et al. (2018) observed positive relationships between species richness and biomass in four forest vegetation layers (tall trees, short trees, shrubs, herbs, and liana). However, the relationship was found to be strongest in the herb layers. The overstorey vegetation with its high productivity may consume additional environmental resources, which would result in reductions of resources that are available for the understorey communities (Zhang et al. 2016). Facilitative effects were found between the shrubs and tree seedings in boreal forests, where the shrubs were observed to increase the tree seedings' environment heterogeneity and growth (Holmgren et al. 2015). These studies show that the BEF relationships at different vertical levels may be different and require further investigation.

The majority of the available information regarding biodiversity and ecosystem functioning relationships still mainly originates from Europe and North America. Complementary studies of Asian forest communities are therefore expected to be of particular interest. China's northeastern temperate coniferous and broad-leaved mixed forests represent an important natural ecosystem in China. The biodiversity and ecosystem functioning studies in these forests are thus essential for the understanding of biomass accumulations and ecosystem functioning. The objective of this study is to examine the correlations between different measures of diversity and aboveground biomass variables in two vertical forest strata based on a large dataset of observations. Three main goals were addressed: (1) to compare the potential of phylogenetic and functional diversity indices and species richness in predicting biomass productivity; (2) to compare the interpretation of niche complementarity, selection effects, or mass-ratio effects on biodiversity and ecosystem functioning relationships; and (3) to assess possible differences in the BEF relationships between the overstorey and understorey layers in the studied ecosystems. Thus, both, the selection effects hypothesis and the mass-ratio hypothesis are evaluated in this study.

\section{Materials and methods}

\subsection{Study site}

The study site was located in the Jiaohe Experimental Forest in Jilin Province. The area was characterized by a temperate continental climate, with an annual average temperature of $3.7^{\circ} \mathrm{C}$. The mean temperature was $21.7^{\circ} \mathrm{C}$ in July, and $-18.6{ }^{\circ} \mathrm{C}$ in January. The mean annual precipitation was $695.9 \mathrm{~mm}$. The soil type was considered to be a dark brown forest soil according to the China Soil Classification (Council 1999), with an average soil depth of $45 \mathrm{~cm}$. A permanent observational field plot of 30 ha $(500 \mathrm{~m} \times 600 \mathrm{~m})$ was established in 2010 at $43^{\circ} 57.928^{\prime}-$ $43^{\circ} 58.214^{\prime} \mathrm{N}, 127^{\circ} 45.287^{\prime}-127^{\circ} 45.790^{\prime} \mathrm{E}$. The forest in the study area was a typical natural coniferous and broadleaved-mixed forest, which had been protected from human disturbances for at least 50 years. The plot was subdivided into 750 cells, each measuring $20 \mathrm{~m} \times 20 \mathrm{~m}$. The elevation, slope, aspect, and convexity were assessed for each cell. The elevation ranged between 576 and $784 \mathrm{~m}$, resulting in an elevational difference between the highest and lowest point of $208 \mathrm{~m}$. All of the woody plants with a breast height diameter (dbh) exceeding $1 \mathrm{~cm}$ were tagged and mapped. Then, their dbh, overall heights, crown widths, and height-to-live crowns were assessed. In this 30 ha observational study, a total of 49,678 woody plants (belonging to 48 species) were surveyed during the summers of 2010 and 2015, and the survey results were recorded. The dominant tree species were found to be Pinus koraiensis, Tilia amurensis, Fraxinus mandshurica, Ulmus laciniata, and Acer mono. The 33 tree species in the study area were represented by at least 30 individuals.

\subsection{Forest strata and biomass estimation}

The woody plant species in the study area were classified as belonging to one of two vertical strata, which are referred to in this study as the "overstorey" and "understorey" layers. In accordance with the classification method put forward by Barrufol et al. (2013), in order to ensure that there was at least one species in each cell, this study used a $10-\mathrm{cm}$ diameter point at breast height as the reference point to distinguish the overstorey and understorey layers. The overstorey layer included 10,133 trees with a dbh $>10 \mathrm{~cm}$, which belonged to 31 species, 20 genera, and 13 families. The understorey layer included all trees with a dbh $\leq 10 \mathrm{~cm}$, with a total of 19,055 woody plants belonging to 28 species, 19 genera, and 12 families (Supplementary Table 1).

The basal area (BA) per cell was calculated as the sum of basal area of each individual in each cell. The aboveground woody biomass (AWB) of all individual trees was calculated using a species-specific allometric growth equation (Supplementary Table 2). The total AWB was calculated as the sum of the aboveground biomass values of all the trees in each $20 \mathrm{~m} \times 20 \mathrm{~m}$ subplot. The aboveground biomass production (ABP) was calculated for each tree as the tree biomass variation during a 5-year period. Only 
those individuals who were present at both inventories were considered, and any dead trees and recruits were ignored.

\subsection{Species, functional traits, and phylogenetic diversity}

Three different criteria were used to express the diversity of the species, functional traits, and phylogeny. The following three indices were used to quantify the taxonomic species diversity (SD):

1. The number of species in each $20 \times 20$ m cell: species richness (sr);

2. The Shannon-Weaver diversity index: $H=-\sum\left(p_{i}\right)\left(\ln p_{i}\right)$;

3. The Simpson diversity index: $D_{S}=1-\sum p_{i}^{2}$.

Where pi is the relative importance of species $i: p_{i}=\frac{N_{i}}{N} ; N_{i}$ is the number of individuals of species $i$; and $N$ is the sum of all the species individuals within the community.

The functional diversity was calculated using the functional traits which reflected the growth potential of the different species (Petchey and Gaston 2002). This study used five functional traits of the overstorey and understorey species as follows: (a) the maximum tree height (Hmax); (b) leaf carbon content (LC); (c) leaf nitrogen content (LN); (d) leaf area (LA); and (e) specific leaf area (SLA). The Hmax was considered to be the maximum height of each species in the study area, and indicated the light acquisition strategy for the species. The four leaf traits reflected the light acquisition capacities, relative weights of the investment costs, and lifetimes (Chave et al. 2009; Wright et al. 2004). The maximum tree heights were measured using a laser range finder (Trupulse360, US). More than sun-exposed 20 leaves were taken from each plant individual and dried in an oven for $48 \mathrm{~h}$. After drying, the leaves were ground for the measurement of elemental content. Leave samples were no less than 30 individuals for each species. The leaf carbon content and leaf nitrogen content were measured using a PE-2400 element analyzer (PerkinElmer Inc., USA). The leaf area was measured with a scanner using samples of five undamaged, sun-exposed leaves collected from more than 30 individual trees in each of the tree species. Also, the specific leaf areas (leaf area/dry matter) were obtained using standard methods (Cornelissen et al. 2003). The averages of each of the species were selected for this study's analysis.

The functional traits were used to calculate functional diversity indices (FD) (including the three indices proposed by Villeger et al. (2008)); functional richness (FRic); functional evenness (FEve); and functional divergence (FDiv). In addition, this study utilized the functional dispersion (FDis) proposed by Laliberte and Legendre (2010). The community-level weighted means (CWM) of each single trait were then calculated for each of the two forest layers.
A plant phylogenetic tree was then constructed for each of the two layers by entering all of the species found in the study area into a phylogenetic database (Phylomatic). This database was essentially a web page which provided phylogenetic information based on a group of plant species classification names which had been submitted by users (http://www. phylodiversity.net; Webb and Donoghue 2005). The Phylomatic system used the Angiosperm Phylogeny Group III (APG III, 2010) as a skeleton. The three phylogenetic diversity indices (PD) were calculated based on this phylogenetic tree as follows: The phylogenetic diversity (pd) which had been defined as the total branch length across the phylogenetic tree of all the species within the community (Faith 1992); the mean pairwise distance (mpd) between all the species in each community; and the mean nearest taxon distance (mntd) defined as the mean distance separating each of the species within the community from its closest relative (Webb et al. 2008). The mpd is generally thought to be more sensitive to the tree-wide patterns of phylogenetic clustering and evenness. Meanwhile, the mntd has been found to be more sensitive to patterns of evenness and clustering closer to the tips of the phylogeny (Liu et al. 2015; Yuan et al. 2016). The PD and FD indices were calculated using the "picante" package (Kembel et al. 2010), and the "FD" package (Laliberte and Legendre 2010), both of which were detailed in the $\mathrm{R}$ package ( $\mathrm{R}$ Core Team 2016).

\subsection{Data analysis}

Linear regression was used to evaluate the relationships between the biomass variables and each diversity index of the two strata. The data sets were standardized by "scale" function prior to further analysis. A linear model was fitted for each diversity-biomass combination. Then, the fit of these models was evaluated by means of the AIC values and their adjusted $R^{2}$. The variables which were used in the model development are listed in Supplementary Table 3. The correlation matrix of all of the independent variables is listed in Supplementary Tables 4 and 5 .

The most parsimonious model was identified based on the aforementioned three diversity index categories (SD, PD, and FD), along with the CWM of each single trait $\left(\mathrm{CWM}_{\mathrm{Hmax}}\right.$, $\mathrm{CWM}_{\mathrm{LC}}, \mathrm{CWM}_{\mathrm{LN}}, \mathrm{CWM}_{\mathrm{LA}}$, and $\left.\mathrm{CWM}_{\mathrm{SLA}}\right)$. This study also followed a previously proposed model simulation method in which the combinations of multiple diversity and specific functional traits provided the most parsimonious explanations of the biomass production (Liu et al. 2015; Yuan et al. 2016). There was little collinearity observed between the functional traits (kappa $=3.85$ in the overstorey; 3.35 in the understorey). Therefore, these were allowed to appear in the same model. The models were compared and ranked using the $\mathrm{R}$ package "MuMIn" (Kamil 2013). The particular method used in this study examined the AIC weights to compare the explanatory 
capabilities of the models. Therefore, it was possible to evaluate whether or not a given model was the most appropriate and parsimonious for describing the observed relationships.

A structural equation model (SEM) was used to examine the relationships between the aboveground biomass, biodiversity indices, and elevations of the two forest layers. Two metamodels were constructed for the two forest vertical strata (Fig. 1). The analysis was based on the covariance matrices and correlation structures between the multiple variables. It was first assumed that the environmental factors affected both species diversity and functional trait diversity. Subsequently, the species diversity determined the phylogenetic diversity, as well as the functional diversity. It was also assumed in this study that the species diversity and biomass of the understorey layer were affected by the overstorey trees (Zhang et al. 2017). The environmental factors and species richness both affected the functional trait diversity, while the functional trait diversity was assumed to directly affect the aboveground biomass and productivity. The species diversity (sr, H, DS); phylogenetic diversity (pd, mpd, mntd); functional diversity (FRic, FEve,

(a) Overstorey

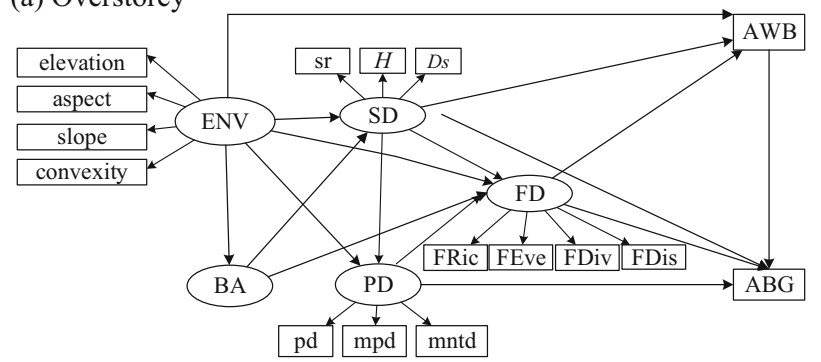

(b) Understorey

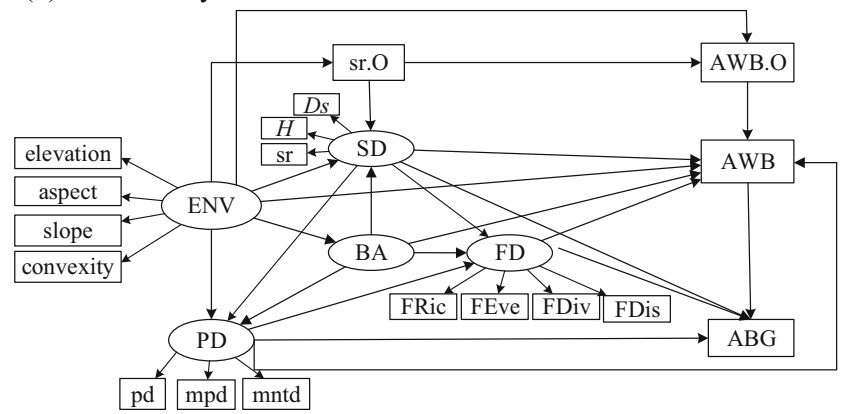

Fig. 1 The Structural equations metamodels in the overstorey a and the understorey b. ENV, SD, PD, and FD are latent variables. ENV represents environment factors, including four observed variables: elevation (ele), aspect (asp); slope (slope), and convexity (con); BA represents basal area; SD represents species diversity, including species richness (sr), the Shannon-Weaver diversity index $(\mathrm{H})$, the Simpson diversity index $\left(\mathrm{D}_{\mathrm{S}}\right)$; PD represents phylogenetic diversity indices, including phylogenetic diversity (pd), the mean pairwise distance (mpd), the mean nearest taxon distance (mntd); FD represents functional diversity, including functional richness (FRic), functional evenness (FEve), functional divergence (FDiv), and functional dispersion (FDis); AWB is aboveground woody biomass; ABP is aboveground biomass production; sr. O represents species richness in the overstorey; AWB. O is the aboveground woody biomass of the overstorey trees
FDiv, FDis); and environmental factors were used to develop a structural equation model for the purpose of evaluating the relationships between the diversity, aboveground biomass (AWB), and biomass production (ABP). It was found that the entire SEM did not pass the fitness test. Therefore, this study gradually reduced the insignificant relationships and relatively insignificant variables. The optimal structural equations were separately obtained for the overstorey and understorey strata layers. The best fit SEM models included the sr, pd., FRic, ele, BA, AWB, and ABP.

A root mean squared error of approximation (RMSEA), along with a goodness-of-fit index (GFI), was used to evaluate the fit of the two structural equation models. An RMSEA value of less than 0.05 indicated a good model fit (McDonald and Ho 2002). A GFI value greater than 0.9 suggested that the model path map effectively fit the observations (Marcoulides and Yuan 2017). A graph of the structural equation models was also developed. The SEM model calculations were performed using AMOS software (Blunch 2012). All other analyses were carried out with the R version 3.3.2 ( $\mathrm{R}$ CoreTeam 2016).

\section{Results}

For all of the woody plants, without any distinction of strata, most of the diversity indices displayed significantly positive correlations with the aboveground woody biomass. Moreover, except leaf area, specific traits as the maximum tree height, specific leaf area, and the carbon content of the leaves, also were found to have positive impacts on the AWB. The community-level weighted means of leaf area had significantly negative effect on AWB. And for ABP, compared with the functional traits and topographical factors, only the basal area and diversity indices showed significantly positive correlations with the ABP. The functional traits and topographical factors had neutral effects on the ABP (Fig. 2).

The correlations between almost all of the diversity indices and biomass production were significantly positive (Fig. 3). The impacts of both the pd and sr on the biomass production were significantly higher than that of the FRic in the overstorey. The impacts of the pd on the biomass production in the overstorey stratum were slightly stronger than that of the sr. However, in the understorey layer, the sr explained more of the variations in the biomass production than pd. The FRic also showed a weak positive correlation with the overstorey biomass production. Furthermore, the relationships between all of the diversity indices and biomass productivity were slightly more pronounced for the overstorey layer than for the understorey (Supplementary Tables 6).

In the two strata layers, three indices of species diversity (sr, H, Ds) and pd were both found to have significantly positive impacts on the AWB and ABP. Also, the pd had a slightly 


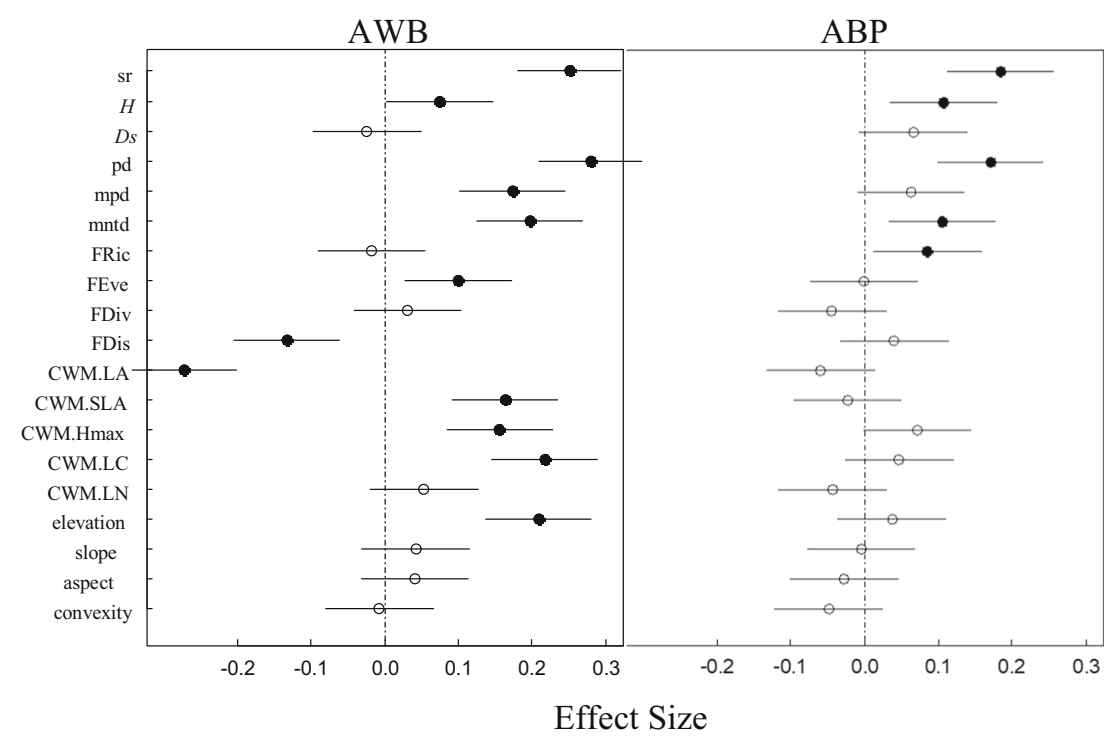

Fig. 2 Univariate regression model results referring to woody plants without any distinction of strata. Left: Relationships between independent variables and aboveground woody biomass (AWB). Right: Relationships between independent variables and aboveground woody biomass production (ABP). Each variable was standardized and their effect size (circles) was compared to determine differences in strength of predictor variables on AWB/ABP. The solid circles represent significant effects $(p<0.05)$. The hollow circles indicate relationships that are not significant $(p>0.05)$. The lines indicate standard errors

observed to have a significantly positive correlation with the AWB and ABP. The community-level weighted means of each single trait were found to have different effects on the AWB and ABP. The $\mathrm{CWM}_{\mathrm{LA}}$ of the overstorey showed a significantly negative impact on the AWB, and an insignificant correlation with the ABP (Fig. 3). stronger effect than other variables in the overstorey. However, in the understorey stratum, the sr showed a stronger effect on the AWB and ABP than the other variables. The FRic displayed a weak correlation with the AWB. However, it showed a significantly positive relationship with the ABP in the overstorey. The FRic in the understorey layer was

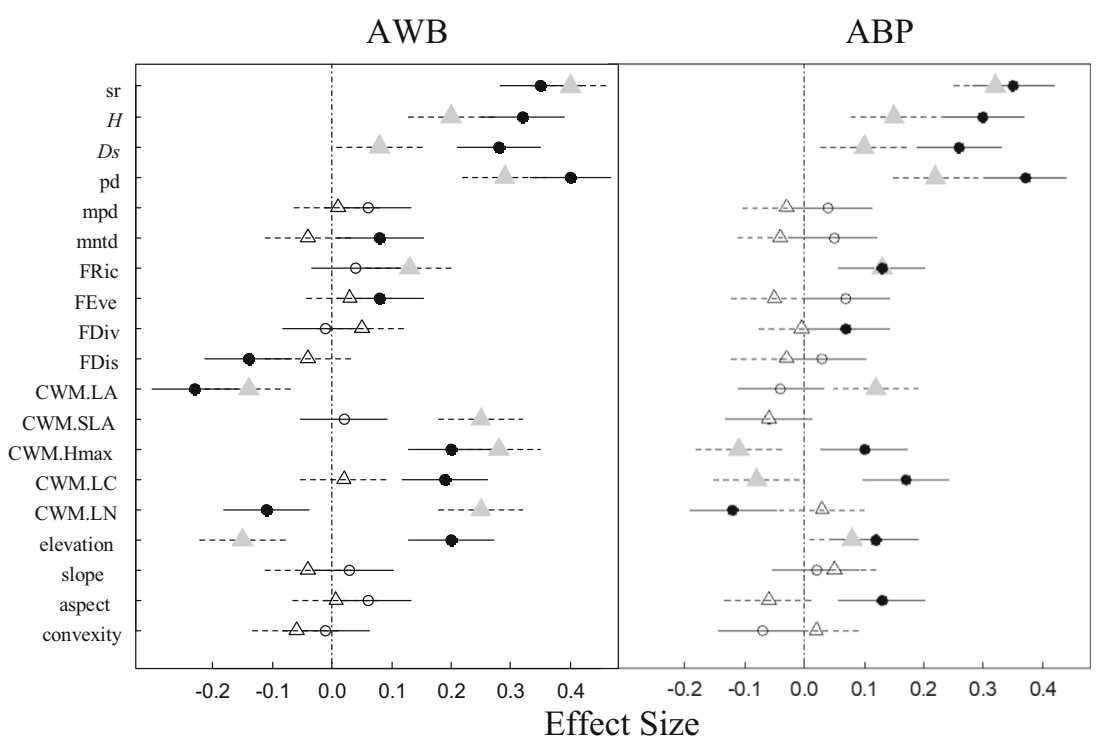

Fig. 3 Univariate regression model results referring to the overstorey (circles) and the understorey (triangles). Left: relationships between independent variables and aboveground woody biomass (AWB). Right: relationships between independent variables and aboveground woody biomass production $(\mathrm{ABP})$. Each variable was standardized and their effect size was compared to determine differences in strength of predictor variables on $\mathrm{AWB} / \mathrm{ABP}$. The solid circles and triangles represent significant effects $(p<0.05)$. The hollow circles and triangles indicate relationships that are not significant $(p>0.05)$. The solid lines indicate standard errors of variables in the overstorey and the dotted lines represent standard errors in the understorey 
In the understorey stratum, the $\mathrm{CWM}_{\mathrm{LA}}$ showed a significantly negative impactm $4 \mathrm{rf} 12$ on the AWB, and significantly positive effects on the ABP. The $\mathrm{CWM}_{\mathrm{Hmax}}$ and $\mathrm{CWM}_{\mathrm{LC}}$ were both found to have significantly positive effects on the AWB and ABP in the overstorey layer. Meanwhile, the $\mathrm{CWM}_{\mathrm{Hmax}}$ and $\mathrm{CWM}_{\mathrm{LC}}$ were both determined to have significantly negative correlations with the ABP in the understorey stratum. In regard to the environmental factors, it was determined that the elevation had significantly positive impact on the AWB of the overstorey and significantly negative effect on the AWB of the understorey. The elevation also was found to have positive correlations with the ABP in the overstorey as well as the understorey layers, as detailed in Fig. 3 and Supplementary Table 7.

The structural equation model of the overstorey explained the observations effectively (RMSEA $=0.00 ; \mathrm{GFI}=1)$. The sr, FRic, and AWB had explained $37 \%$ of the ABP of the canopy trees. The elevations had negative effects on the species and functional richness in the overstorey stratum, and positive effects on the AWB. The pd positively affected the FRic, while the FRic had an insignificantly positive effect on the AWB. It was found that the sr and FRic had negative correlations, and the pd had a significantly positive effect on the FRic. Furthermore, the sr, FRic, and AWB affected the ABP positively, with the AWB having the greatest impact, as shown in Fig. 4 a.

The understorey observations could be effectively explained by the structural equation model (RMSEA $=0.029$; GFI $=$ 0.998 ), in which $41 \%$ of the ABP variations were explained. The richness of the tree species in the overstorey stratum was found to have positive effects on the understorey tree species richness, and significantly negative effects on the ABP of understorey tree. The aboveground woody biomass of the understorey trees was significantly affected by the sr and pd of the understorey layer. The sr and AWB of the understorey had positive effects on the ABP of the understorey. However, the sr and AWB of the overstorey stratum were observed to have negative effects on the understorey ABP. In addition, the effects of the elevations on the species richness and functional richness of understorey plants were weaker than that of the overstorey trees in Fig. 4 b.

Multivariate linear models were used to assess the relationships between the diversity indices and the biomass. It was found that combinations of the diversity indices and the CWM of the functional traits could explain more of the variations in the biomass and biomass production. These combinations specifically included FDis, FRic, pd, and some functional traits which explained the AWB more effectively, while the ABP variations were explained by combinations of the FDis, FDiv, FRic, pd, sr, and functional traits (Table 1). However, the combination of the FDis, FEve, sr, and functional traits showed higher explanations of the AWB and ABP in the understorey, as shown in Table 2. The functional traits which explained more AWB in the overstorey were the specific leaf area, maximum tree height, and leaf carbon content. The particular traits which showed higher explanatory power with regard to the ABP of the overstorey stratum were determined to be the leaf traits (leaf carbon content, leaf area, and specific leaf area). The maximum tree height, leaf carbon content, and specific leaf area explained more of the variations in the AWB of the understorey, while the leaf area and specific leaf area explained more variations of the ABP of the understorey. Also, this study found that the LN did not display any significant effects in the multiple regression models for the prediction of the biomass in both strata layers.

\section{Discussion}

\subsection{Phylogenetic and functional diversities are less effective predictors of biomass production than species richness}

In the comparisons of the relationships of the different diversity indices with the aboveground biomass production, the phylogenetic diversity (pd) did not significantly emerge as a better predictor when compared with species richness (cf. Cadotte 2015). The effect of $\mathrm{pd}$ on biomass and biomass production proved to be slightly greater than the effect of sr, which differed from the observations made in the understorey stratum. These findings suggest that the advantages of the pd were only manifested in the overstorey layer where the trees had larger dimensions (Cadotte et al. 2008; Zhang et al. 2017). A possible reason for this result may be that the pd had increased with increasing richness of the functional traits, which in turn has led to increased biomass yields. The pd showed a positive relationship with the FRic, which indicated greater niche complementarity (Cadotte 2015; Cadotte et al. 2009). However, the weaker advantage of the pd may also have been the result of many species belonging to the same family (Kelly et al. 2014).

We found that the functional diversity indices displayed no advantages in predicting the aboveground biomass in the study area. Only the FRic showed a significantly positive correlation with the aboveground biomass production in the two layers. Other functional indices had an almost zero effect on the ABP. These findings were consistent with the results presented by Fotis et al. (2018), where the functional diversity indices had neutral relationships with the aboveground biomass in mixed mesophytic temperate forests of the eastern USA. Szwagrzyk and Gazda (2007) found that functional diversity had negative effects on the aboveground biomass across 100 temperate forests in Central Europe, which was similar to the relationship between the FDis and AWB in our overstorey stratum. In addition, the analyses regarding the functional traits and ecosystem functions confirmed that the CWM traits provided better explanations, while the functional diversity indices (such as the FDis) showed weak 


\section{(a) Overstorey}

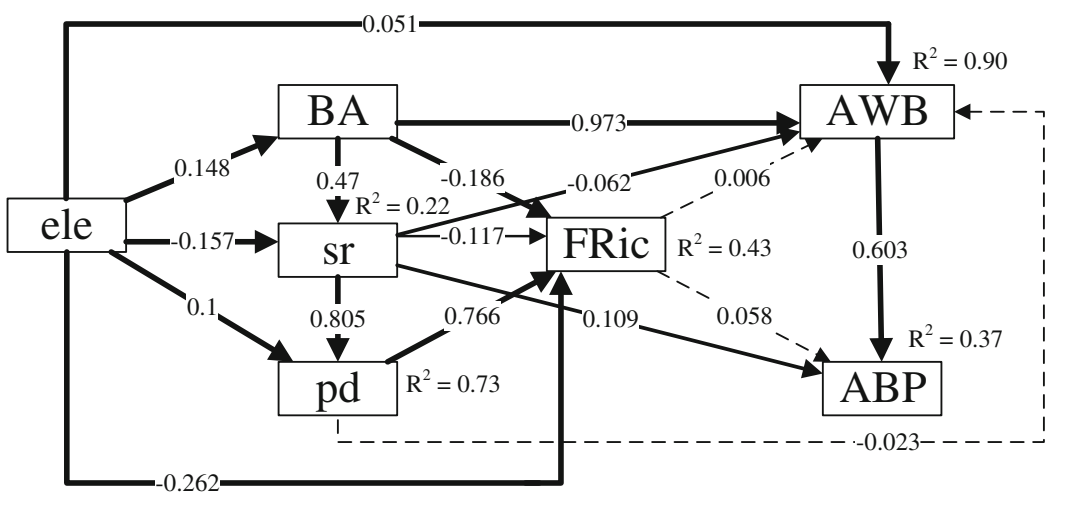

RMSEA $=0.00 ; \mathrm{GFI}=1.00$

\section{(b) Understorey}

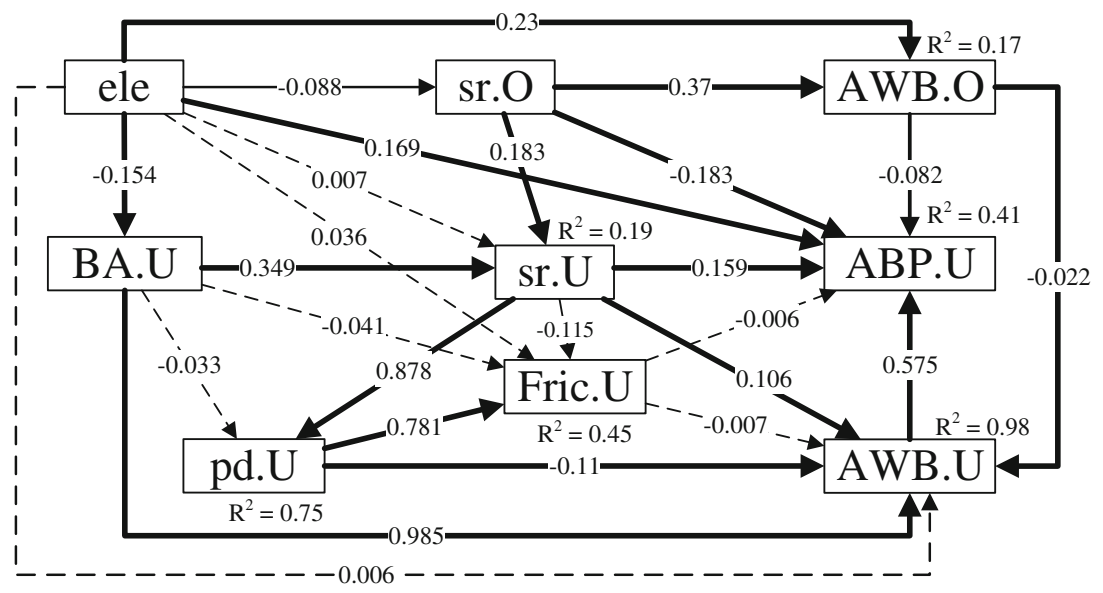

RMSEA $=0.029 ; \mathrm{GFI}=0.998$

Fig. 4 Structural equations for linking the aboveground biomass and biodiversity in the overstorey $\mathbf{a}$ and the understorey $\mathbf{b}$. a-ele is elevation; BA is basal area; pd. is phylogenetic diversity; sr is species richness; FRic is functional richness; AWB is aboveground woody biomass; ABP is aboveground biomass production. $\mathbf{b}-\mathrm{sr}$.O is species richness of the overstorey; BA.U is basal area of the understorey; sr.U is species richness of the understorey; pd.U is phylogenetic diversity of the understorey; ele is elevation; FRic.U is functional trait richness of

correlations with the functions (Finegan et al. 2015; Kunstler et al. 2015). The weaker relationships between the ABP and the functional diversity, when compared with that of the species taxonomic diversity and the ABP, were believed to have two possible causes. One cause may have been that the previous analyses had correlated the trait means and dissimilarities with the overall biomass, and had not considered the performance components of the polycultures relative to those expected from monocultures (Cadotte 2017). It may also have been that the functional traits used in this study were not sufficiently comprehensive or accurate regarding the entire forest area, or that they were not the dominant traits which could greatly affect the biomass accumulation of this particular forest community. understorey; AWB.O is aboveground woody biomass of the overstorey; ABP.U is aboveground biomass increment of understorey: AWB.U is aboveground woody biomass of understorey. The dashed lines represent insignificant relationships $(p>0.05)$. The solid line from fine to coarse represents the significance of different relationships $(p<0.05, p<0.01$, $p<0.001)$. The correlation coefficients are shown above the corresponding lines

\subsection{BEF relationship and the effects of the functional traits}

The relationships between the biodiversity and aboveground biomass and biomass production in Jiaohe supported the general findings of previous studies, in which the correlation between the species diversity and biomass productivity in a forest ecosystem is positive (Liang et al. 2016; Paquette and Messier 2011; Yuan et al. 2016; Zhang et al. 2012, 2017). Other studies found neutral and even negative relationships between forest biomass productivity and species diversity (Fahey et al. 2015; Gadow et al. 2016; Fotis et al. 2018; Hardiman et al. 2011). These 
Table 1 Comparison of multiple linear regression model results predicting biomass in the overstorey

\begin{tabular}{|c|c|c|c|c|c|c|}
\hline Dependent variable & Model & df & $\log$ Lik & $\mathrm{AICc}$ & Delta & $R^{2}$ \\
\hline \multirow[t]{5}{*}{ AWB } & $\sim \mathrm{CWM}_{\mathrm{LC}}+\mathrm{CWM}_{\mathrm{Hmax}}+\mathrm{CWM}_{\mathrm{SLA}}+\mathrm{FDis}+\mathrm{FRic}+\mathrm{pd}$ & 8 & -950.57 & 1917.33 & 0 & 0.25 \\
\hline & $\sim \mathrm{CWM}_{\mathrm{H} \max }+\mathrm{FDis}+\mathrm{FRic}+\mathrm{pd}$ & 6 & -952.71 & 1917.54 & 0.20 & 0.25 \\
\hline & $\sim \mathrm{CWM}_{\mathrm{Hmax}}+\mathrm{CWM}_{\mathrm{SLA} .}+\mathrm{FDis}+\mathrm{FRic}+\mathrm{pd}$ & 7 & -951.79 & 1917.74 & 0.40 & 0.25 \\
\hline & $\sim \mathrm{CWM}_{\mathrm{Hmax}}+\mathrm{FDis}+\mathrm{FEve}+\mathrm{FRic}+\mathrm{pd}$ & 7 & -951.81 & 1917.76 & 0.43 & 0.25 \\
\hline & $\sim \mathrm{CWM}_{\mathrm{LC}}+\mathrm{CWM}_{\mathrm{Hmax}}+\mathrm{CWM}_{\mathrm{SLA}}+\mathrm{FDis}+\mathrm{FRic}+\mathrm{pd} .+\mathrm{sr}$ & 9 & -949.80 & 1917.84 & 0.51 & 0.26 \\
\hline \multirow[t]{5}{*}{$\mathrm{ABP}$} & $\sim \mathrm{CWM}_{\mathrm{LC}}+\mathrm{CWM}_{\mathrm{LA}}+\mathrm{CWM}_{\mathrm{SLA}}+\mathrm{FDis}+\mathrm{FDiv}+\mathrm{FRic}+\mathrm{pd} .+\mathrm{sr}$ & 10 & -995.24 & 2010.78 & 0 & 0.16 \\
\hline & $\sim \mathrm{CWM}_{\mathrm{LC}}+\mathrm{CWM}_{\mathrm{H} \max }+\mathrm{CWM}_{\mathrm{LA}}+\mathrm{CWM}_{\mathrm{SLA} .}+\mathrm{FDis}+\mathrm{FDiv}+\mathrm{FRic}+\mathrm{pd} .+\mathrm{sr}$ & 11 & -994.44 & 2011.24 & 0.46 & 0.16 \\
\hline & $\sim \mathrm{CWM}_{\mathrm{LC}}+\mathrm{CWM}_{\mathrm{LA}}+\mathrm{CWM}_{\mathrm{SLA}}+\mathrm{FDis}+\mathrm{FRic}+\mathrm{pd} .+\mathrm{sr}$ & 9 & -996.71 & 2011.65 & 0.88 & 0.16 \\
\hline & $\sim \mathrm{CWM}_{\mathrm{LC}}+\mathrm{CWM}_{\mathrm{LA}}+\mathrm{CWM}_{\mathrm{SLA}}+\mathrm{FDis}+\mathrm{FDiv}+\mathrm{FEve}+\mathrm{FRic}+\mathrm{pd} .+\mathrm{sr}$ & 11 & -994.96 & 2012.29 & 1.51 & 0.16 \\
\hline & $\sim \mathrm{CWM}_{\mathrm{LC}}+\mathrm{CWM}_{\mathrm{Hmax}}+\mathrm{CWM}_{\mathrm{LA}}+\mathrm{CWM}_{\mathrm{SLA} .}+\mathrm{FDis}+\mathrm{FRic}+\mathrm{pd} .+\mathrm{sr}$ & 10 & -996.05 & 2012.39 & 1.61 & 0.16 \\
\hline
\end{tabular}

AWB is aboveground woody biomass; $\mathrm{ABP}$ is aboveground biomass production. pd is phylogenetic diversity; sr is species richness; FRic is functional richness; FDis is functional dispersion; FDiv is functional divergence. $\mathrm{CWM}_{\mathrm{LC}}$ is community-level weighted means of leaf carbon content; $\mathrm{CWM}_{\mathrm{Hmax}}$ is community-level weighted means of the maximum tree height; $\mathrm{CWM}_{\mathrm{LA}}$ is community-level weighted means of leaf area; $\mathrm{CWM}_{\mathrm{SLA}}$ is community-level weighted means of specific leaf area

different results may have been caused by variations in the spatial scale. Chisholm et al. (2013) found that the size of subplots can change the relationship between diversity and productivity, which is positive at smaller spatial scales (0.04-0.1 ha) and neutral or negative at larger scales (0.25-1 ha) (Fotis et al. 2018; Poorter et al. 2015). The majority of the ten diversity indices which were used showed positive correlations with the AWB and ABP in both layers. Greater diversity resulting in higher biomass production suggests that niche complementarity in our study area (weak interspecific competition leading to high resource utilization) had played an important role (Loreau 2000; Madrigal-González et al. 2016a).

The CWM of the functional traits was found to have completely different impacts on the AWB and ABP in the two vertical layers. The $\mathrm{CWM}_{\mathrm{LA}}$ had more significantly negative effects on the AWB in the overstorey than in the understorey stratum. This may have been caused by the fact that the overstorey trees were exposed to higher solar radiation and leaf-to-air vapor pressure deficits than the trees in the relatively buffered understorey level (Roberts et al. 1990). This may have made it impossible for the upper canopy leaves to maintain hydraulic safety, while simultaneously opening the stomata sufficiently to maintain a positive carbon balance and regulation of leaf temperature (through transpirative cooling) under the conditions of lower water availability and higher evaporative demands (natural droughts only) (Bennett et al. 2015). The $\mathrm{CWM}_{\mathrm{LA}}$ showed a positive impact on the ABP in the understorey, due to the fact that the trees in the understorey stratum survived under the shade of the canopy trees with their larger leaf areas.

Table 2 Comparison of multiple linear regression model results predicting biomass in the understorey

\begin{tabular}{|c|c|c|c|c|c|c|}
\hline Dependent variable & Model & df & $\operatorname{logLik}$ & $\mathrm{AICc}$ & Delta & $R^{2}$ \\
\hline \multirow[t]{5}{*}{ AWB } & $\sim \mathrm{CWM}_{\mathrm{LC}}+\mathrm{CWM}_{\mathrm{H} \max }+\mathrm{CWM}_{\mathrm{SLA}}+\mathrm{FDis}+\mathrm{FDiv}+\mathrm{FEve}+\mathrm{mntd}+\mathrm{pd} .+\mathrm{sr}$ & 11 & -893.01 & 1808.38 & 0 & 0.36 \\
\hline & $\sim \mathrm{CWM}_{\mathrm{LC}}+\mathrm{CWM}_{\mathrm{Hmax}}+\mathrm{CWM}_{\mathrm{SLA}}+\mathrm{FDis}+\mathrm{FDiv}+\mathrm{FEve}+\mathrm{mntd}+\mathrm{mpd}+\mathrm{sr}$ & 11 & -893.32 & 1809.01 & 0.62 & 0.16 \\
\hline & $\sim \mathrm{CWM}_{\mathrm{LC}}+\mathrm{CWM}_{\mathrm{H} \max }+\mathrm{CWM}_{\mathrm{SLA}}+\mathrm{FDis}+\mathrm{FDiv}+\mathrm{FEve}+\mathrm{mntd}+\mathrm{pd}$ & 10 & -894.38 & 1809.06 & 0.68 & 0.36 \\
\hline & $\sim \mathrm{CWM}_{\mathrm{LC}}+\mathrm{CWM}_{\mathrm{Hmax}}+\mathrm{CWM}_{\mathrm{LA}}+\mathrm{CWM}_{\mathrm{SLA}}+\mathrm{FDis}+\mathrm{FDiv}+\mathrm{FEve}+\mathrm{mntd}+\mathrm{pd} .+\mathrm{sr}$ & 12 & -892.55 & 1809.52 & 1.14 & 0.36 \\
\hline & $\sim \mathrm{CWM}_{\mathrm{LC}}+\mathrm{CWM}_{\mathrm{Hmax}}+\mathrm{FDis}+\mathrm{FDiv}+\mathrm{FEve}+\operatorname{mntd}+\mathrm{pd} .+\mathrm{sr}$ & 10 & -894.75 & 1809.80 & 1.41 & 0.36 \\
\hline \multirow[t]{5}{*}{$\mathrm{ABP}$} & $\sim \mathrm{CWM}_{\mathrm{LA}}+\mathrm{CWM}_{\mathrm{SLA}}+\mathrm{FDis}+\mathrm{FEve}+\mathrm{sr}$ & 7 & -995.04 & 2004.24 & 0.00 & 0.16 \\
\hline & $\sim \mathrm{CWM}_{\mathrm{LA}}+\mathrm{CWM}_{\mathrm{SLA}}+\mathrm{FDis}+\mathrm{FEve}+\mathrm{mpd}+\mathrm{sr}$ & 8 & -994.05 & 2004.29 & 0.46 & 0.16 \\
\hline & $\sim \mathrm{CWM}_{\mathrm{LA}}+\mathrm{CWM}_{\mathrm{SLA}}+\mathrm{FDis}+\mathrm{FDiv}+\mathrm{FEve}+\mathrm{sr}$ & 8 & -994.13 & 2004.46 & 0.88 & 0.16 \\
\hline & $\sim \mathrm{CWM}_{\mathrm{LA}}+\mathrm{CWM}_{\mathrm{SLA}}+\mathrm{FDis}+\mathrm{FEve}+\mathrm{mntd}+\mathrm{sr}$ & 8 & -994.14 & 2004.48 & 1.51 & 0.16 \\
\hline & $\sim \mathrm{CWM}_{\mathrm{Hmax}}+\mathrm{CWM}_{\mathrm{LA}}+\mathrm{CWM}_{\mathrm{SLA}}+\mathrm{FDis}+\mathrm{FDiv}+\mathrm{FEve}+\mathrm{sr}$ & 9 & -993.12 & 2004.49 & 1.61 & 0.16 \\
\hline
\end{tabular}

AWB is aboveground woody biomass; ABP is aboveground biomass production. pd is phylogenetic diversity; mntd is the mean nearest taxon distance; $\mathrm{sr}$ is species richness; FEve is functional evenness; FDis is functional dispersion; FDiv is functional divergence. $\mathrm{CWM}_{\mathrm{LC}}$ is community-level weighted means of leaf carbon content; $\mathrm{CWM}_{\mathrm{Hmax}}$ is community-level weighted means of the maximum tree height; $\mathrm{CWM}_{\mathrm{LA}}$ is community-level weighted means of leaf area; $\mathrm{CWM}_{\mathrm{SLA}}$ is community-level weighted means of specific leaf area 
The $\mathrm{CWM}_{\mathrm{Hmax}}$ showed a positive correlation with the AWB in both the overstorey and understorey layers. The tall species tend to have high AWB and ABP in the taller closed canopy systems, which underlines the potential importance of the adult individuals for the growth and survival of the forest (Finegan et al. 2015; Wright et al. 2010). The $\mathrm{CWM}_{\mathrm{LC}}$ was observed to have significantly positive correlations with both the AWB and ABP in the overstorey, while only weak impacts on the AWB in the understorey. The high carbon content in the community indicated that the accumulation rate of the organic matter was high. Therefore, it was concluded that there was a positive correlation between the leaf carbon content and biomass production (Hao et al. 2018). In contrast, the $\mathrm{CWM}_{\mathrm{LN}}$ displayed significantly negative impacts on the AWB and $\mathrm{ABP}$ in the overstorey and positive in the understorey. The reasons for these results may have been that the high $\mathrm{CWM}_{\mathrm{LN}}$ meant that there were more plants with high leaf nitrogen content in the community. These were mainly conifers in the current study, such as Pinus koraiensis, which are characterized by slow growth rates resulting in small biomass production (Hutchins et al. 1996). The effects of the CWM on the biomass production of all the woody trees were not significant. This may have been due to the fact that the opposing effects of the CWM on the ABP in the two strata, which greatly weakened the overall effects of the CWM on the tree community without distinction of strata.

The observed correlations between the CWM specific traits and the AWB and ABP were significant in both strata. The various combinations of the diversity indices and functional traits explained more of the biomass and productivity variations. This was consistent with previous results, which suggested that niche complementarity only partly explained the BEF relationships (Feng et al. 2011; Finegan et al. 2015; Liu et al. 2015; Paquette and Messier 2011). Mass-ratio and selection effects also played a role in influencing biomass production in our study. However, the relative importance of the niche complementarity, selection effects, and mass-ratio effects in explaining ecosystem functioning is a complex issue which requires further research (Cadotte 2017; Finegan et al. 2015; Fotis et al. 2018).

\subsection{Differences in the BEF relationships in the two strata}

The effects of biodiversity on biomass and biomass productivity were lightly stronger in the trees of the overstorey than in the understorey trees. The magnitudes and directions of the BEF relationships were affected by the surrounding environmental conditions and available resources (Díaz and Cabido 2001; Fridley 2002). Different tree sizes lead to differences in competitiveness, so stand basal area could be used as proxy for competition intensity (Paquette and Messier 2011). In our study area, the aboveground woody biomass is determined mostly by the stand basal area in two strata. And same is found in species richness, which is also strongly effected by basal area. However, the effect of basal area on aboveground biomass production in the overstorey is stronger than it in the understorey. The competition intensity of overstorey trees is greater than that of the understorey trees, and overstorey trees (mean basal area $=22.98 \mathrm{~m}^{2} / \mathrm{ha}$ ) can restrict the growth of the understorey trees (mean basal area $=1.28 \mathrm{~m}^{2} / \mathrm{ha}$ ) by competition and resource utilization (Gilliam 2007; Mason et al. 2011). The negative effects of the overstorey biomass on the productivity of the understorey biomass confirmed these findings (cf. Bartels and Chen 2013; Zhang et al. 2016). The resource-constraining effects of the overstorey trees resulted in the reduced resource-use efficiency of the understorey trees (Hooper et al. 2005). Similar findings were presented by Mason et al. (2011) when describing the niche overlapping effects of woody plants. Also, there were differences observed in the light utilization patterns between the overstorey and understorey trees. The smaller trees used the light sources for shorter periods of time during the day depending on the size of overstorey tree canopy. This may explain why the above ground biomass of the overstorey trees had a negative effect on the biomass production of the understorey trees (Madrigal-González et al. 2016b).

The correlations between the overstorey and understorey tree species richness were found to be positive, which was consistent with previous studies (Gamfeldt et al. 2013; Zhang et al. 2017). The positive relationships between woody plant species richness in the different vertical strata may have been due to different responses to climate, soil, and space utilizations (Taylor et al. 2014). The greater species richness in the overstorey layer caused greater environmental heterogeneity in the understorey layer, due to the variations in the litter and light penetrations (Barrufol et al. 2013; Bartels and Chen 2013). Also, the various root systems had different rates of soil nutrient absorption, which may have also affected the species biomass accumulation (Houle et al. 2014) and resulted in greater species numbers in the understorey. The complementarity and mutual promotion in the two strata has also been found in subtropical, temperate, and boreal forests (Ali and Yan 2017; Zhang et al. 2017). In grassland experiments, it was found that the differences in leaf phenology potentially determined the length of time that light could be captured, which was assumed to be associated with species coexistence (Mason et al. 2013). It is believed that niche complementarity may be important for the promotion of a positive diversityproductivity relationship of understorey trees. The complementary effects were found to be more beneficial to the survival of the tree species due to their impacts on the temporal and spatial environmental heterogeneity of the overstorey trees (Fridley 2002; Hooper et al. 2005).

In this study, elevation had a greater positive effect on the aboveground biomass of the overstorey when compared with 
that of the understorey biomass. Elevation was negatively correlated with overstorey tree species richness, while the effects of elevation on the understorey species richness were weak. These results indicate that elevation played a role in screening the richness of the overstorey species without limiting their growth. The resource filtration of the overstorey vegetation not only affected the intensity of the relationships between the diversity and aboveground biomass, but also affected the richness of the understorey species' responses to the environment (Taylor et al. 2014). The effects of the overstorey trees and elevation on the BEF relationships of the understorey trees indirectly indicated that there was no single, general relationship between the diversity and productivity in this particular natural community. The intensities of these relationships were found to be largely affected by the environmental conditions (Díaz and Cabido 2001; Fridley 2002; Zhang et al. 2016).

Many studies have shown that climate and local site conditions will affect species diversity, aboveground biomass, and productivity as well as their direct or indirect relationships (Zhang et al. 2016; Ali and Yan 2017; Li et al. 2018). The climate and soil factors have different effects on plant diversity and biomass at different strata in different regions. This study only analyses correlations without hypothesizing causal effects. We are aware that the same non-measured factors may cause differences in both diversity and production, especially possible fertility effects, e.g., spatial differences in soil nutrient and moisture availability. These factors should be included in future studies to explain differences in diversity and production in greater detail.

Funding This research is supported by the Key Project of National Key Research and Development Plan (2017YFC0504104) and the Program of National Natural Science Foundation of China (31670643).

Data availability The datasets generated during and/or analyzed during the current study are available from the corresponding author on reasonable request.

\section{Compliance with ethical standards}

Conflicts of interest The authors declare that they have no conflict of interest and that experiments comply with the current laws in China.

\section{References}

Ali A, Yan E-R (2017) The forest strata-dependent relationship between biodiversity and aboveground biomass within a subtropical forest. For Ecol Manag 401:125-134. https://doi.org/10.1016/j.foreco. 2017.06.056

Balvanera P et al (2013) Linking biodiversity and ecosystem services: current uncertainties and the necessary next steps. BioScience: bit003

Barrufol M, Schmid B, Bruelheide H, Chi X, Hector A, Ma K, Michalski S, Tang Z, Niklaus PA (2013) Biodiversity promotes tree growth during succession in subtropical forest. PLoS One 8:e81246. https:// doi.org/10.1371/journal.pone.0081246

Bartels SF, Chen HY (2013) Interactions between overstorey and understorey vegetation along an overstorey compositional gradient. J Veg Sci 24:543-552

Bennett AC, McDowell NG, Allen CD, Anderson-Teixeira KJ (2015) Larger trees suffer most during drought in forests worldwide. Nature Plants 1:15139. https://doi.org/10.1038/nplants.2015.139

Blunch N (2012) Introduction to structural equation modeling using IBM SPSS statistics and AMOS. Sage

Cadotte MW (2015) Phylogenetic diversity and productivity: gauging interpretations from experiments that do not manipulate phylogenetic diversity. Funct Ecol 29:1603-1606. https://doi.org/10.1111/ 1365-2435.12543

Cadotte MW (2017) Functional traits explain ecosystem function through opposing mechanisms. Ecol Lett 20:989-996. https://doi.org/10. 1111/ele. 12796

Cadotte MW, Cardinale BJ, Oakley TH (2008) Evolutionary history and the effect of biodiversity on plant productivity. Proc Natl Acad Sci U S A 105:17012-17017. https://doi.org/10.1073/pnas.0805962105

Cadotte MW, Cavender-Bares J, Tilman D, Oakley TH (2009) Using phylogenetic, functional and trait diversity to understand patterns of plant community productivity. PLoS One 4:e5695. https://doi. org/10.1371/journal.pone.0005695

Cadotte MW, Jonathan Davies T, Regetz J, Kembel SW, Cleland E, Oakley TH (2010) Phylogenetic diversity metrics for ecological communities: integrating species richness, abundance and evolutionary history. Ecol Lett 13:96-105. https://doi.org/10.1111/j. 1461-0248.2009.01405.x

Cardinale BJ, Srivastava DS, Duffy JE, Wright JP, Downing AL, Sankaran M, Jouseau C (2006) Effects of biodiversity on the functioning of trophic groups and ecosystems. Nature 443:989-992. https://doi.org/10.1038/nature05202

Chave J, Coomes D, Jansen S, Lewis SL, Swenson NG, Zanne AE (2009) Towards a worldwide wood economics spectrum. Ecol Lett 12:351366. https://doi.org/10.1111/j.1461-0248.2009.01285.x

Chisholm RA, Muller-Landau HC, Abdul Rahman K, Bebber DP, Bin Y, Bohlman SA, Bourg NA, Brinks J, Bunyavejchewin S, Butt N, Cao H, Cao M, Cárdenas D, Chang LW, Chiang JM, Chuyong G, Condit R, Dattaraja HS, Davies S, Duque A, Fletcher C, Gunatilleke N, Gunatilleke S, Hao Z, Harrison RD, Howe R, Hsieh CF, Hubbell SP, Itoh A, Kenfack D, Kiratiprayoon S, Larson AJ, Lian J, Lin D, Liu H, Lutz JA, Ma K, Malhi Y, McMahon S, McShea W, Meegaskumbura M, Mohd. Razman S, Morecroft MD, Nytch CJ, Oliveira A, Parker GG, Pulla S, Punchi-Manage R, Romero-Saltos H, Sang W, Schurman J, Su SH, Sukumar R, Sun IF, Suresh HS, Tan S, Thomas D, Thomas S, Thompson J, Valencia R, Wolf A, Yap S, Ye W, Yuan Z, Zimmerman JK (2013) Scale-dependent relationships between tree species richness and ecosystem function in forests. J Ecol 101:1214-1224. https://doi.org/10.1111/1365-2745. 12132

Cornelissen JHC, Lavorel S, Garnier E, Díaz S, Buchmann N, Gurvich DE, Reich PB, Steege H, Morgan HD, Heijden MGA, Pausas JG, Poorter H (2003) A handbook of protocols for standardised and easy measurement of plant functional traits worldwide. Aust J Bot 51: 335-380. https://doi.org/10.1071/BT02124

Council CS (1999) Soil agricultural chemical analysis procedure. Chinese Agricultural Science Press, Beijing

Díaz S, Cabido M (2001) Vive la difference: plant functional diversity matters to ecosystem processes. Trends Ecol Evol 16:646-655

Díaz S, Lavorel S, de Bello F, Quétier F, Grigulis K, Robson TM (2007) Incorporating plant functional diversity effects in ecosystem service assessments. Proc Natl Acad Sci 104:20684-20689. https://doi.org/ 10.1073/pnas.0704716104

Fahey RT, Fotis AT, Woods KD (2015) Quantifying canopy complexity and effects on productivity and resilience in late-successional 
hemlock-hardwood forests. Ecol Appl 25:834-847. https://doi.org/ 10.1890/14-1012.1

Faith DP (1992) Conservation evaluation and phylogenetic diversity. Biol Conserv 61:1-10. https://doi.org/10.1016/0006-3207(92)91201-3

Feng G, Zhang J, Pei N, Rao M, Mi X, Ren H, Ma K (2011) Comparison of phylobetadiversity indices based on community data from Gutianshan forest plot. Chin Sci Bull 57:623-630. https://doi.org/ 10.1007/s11434-011-4869-1

Finegan B, Peña-Claros M, de Oliveira A, Ascarrunz N, Bret-Harte MS, Carreño-Rocabado G, Casanoves F, Díaz S, Eguiguren Velepucha P, Fernandez F, Licona JC, Lorenzo L, Salgado Negret B, Vaz M, Poorter L (2015) Does functional trait diversity predict aboveground biomass and productivity of tropical forests? Testing three alternative hypotheses. J Ecol 103:191-201. https://doi.org/10.1111/ 1365-2745.12346

Fotis AT, Murphy SJ, Ricart RD, Krishnadas M, Whitacre J, Wenzel JW, Queenborough SA, Comita LS (2018) Above-ground biomass is driven by mass-ratio effects and stand structural attributes in a temperate deciduous forest. J Ecol 106:561-570. https://doi.org/10. 1111/1365-2745.12847

Fowler MS, Laakso J, Kaitala V, Ruokolainen L, Ranta E (2012) Species dynamics alter community diversity-biomass stability relationships. Ecol Lett 15:1387-1396

Fox JW (2005) Interpreting the 'selection effect' of biodiversity on ecosystem function. Ecol Lett 8:846-856. https://doi.org/10.1111/j. 1461-0248.2005.00795.x

Fridley JD (2002) Resource availability dominates and alters the relationship between species diversity and ecosystem productivity in experimental plant communities. Oecologia 132:271-277

Gadow KV, Zhang GQ, Durrheim G, Drew D, Seydack A (2016) Diversity and production in an afromontane forest. For Ecosyst 3: 15. https://doi.org/10.1186/s40663-016-0074-7

Gamfeldt L, Snäll T, Bagchi R, Jonsson M, Gustafsson L, Kjellander P, Ruiz-Jaen MC, Fröberg M, Stendahl J, Philipson CD, Mikusiński G, Andersson E, Westerlund B, Andrén H, Moberg F, Moen J, Bengtsson J (2013) Higher levels of multiple ecosystem services are found in forests with more tree species. Nat Commun 4:1340. https://doi.org/10.1038/ncomms 2328

Gilliam FS (2007) The ecological significance of the herbaceous layer in temperate forest ecosystems. Bioscience 57:845-858. https://doi. org/10.1641/b571007

Grime JP (1998) Benefits of plant diversity to ecosystems: immediate, filter and founder effects. J Ecol 86:902-910. https://doi.org/10. 1046/j.1365-2745.1998.00306.x

Hao M, Zhang C, Zhao X, Gadow Kv (2018) Functional and phylogenetic diversity determine woody productivity in a temperate forest. Ecol Evol 8:2395-2406 doi:https://doi.org/10.1002/ece3.3857

Hardiman BS, Bohrer G, Gough CM, Vogel CS, Curtis PS (2011) The role of canopy structural complexity in wood net primary production of a maturing northern deciduous forest. Ecology 92:1818-1827. https://doi.org/10.1890/10-2192.1

Holmgren M, Lin CY, Murillo JE, Nieuwenhuis A, Penninkhof J, Sanders N, van Bart T, van Veen H, Vasander H, Vollebregt ME, Limpens J (2015) Positive shrub-tree interactions facilitate woody encroachment in boreal peatlands. J Ecol 103:58-66. https://doi.org/10. 1111/1365-2745.12331

Hooper DU, Chapin FS III, Ewel JJ, Hector A, Inchausti P, Lavorel S, Lawton JH, Lodge DM, Loreau M, Naeem S, Schmid B, Setälä H, Symstad AJ, Vandermeer J, Wardle DA (2005) Effects of biodiversity on ecosystem functioning: a consensus of current knowledge. Ecol Monogr 75:3-35. https://doi.org/10.1890/04-0922

Houle D, Moore J-D, Ouimet R, Marty C (2014) Tree species partition N uptake by soil depth in boreal forests. Ecology 95:1127-1133

Hutchins HE, Hutchins SA, Liu B-w (1996) The role of birds and mammals in Korean pine (Pinus koraiensis) regeneration dynamics. Oecologia 107:120-130. https://doi.org/10.1007/bf00582242
Kamil B (2013) MuMIn: multi-model inference. R package version 1.9. 5 project for statistical computing

Kelly S, Grenyer R, Scotland RW (2014) Phylogenetic trees do not reliably predict feature diversity. Divers Distrib 20:600-612

Kembel SW, Cowan PD, Helmus MR, Cornwell WK, Morlon H, Ackerly DD, Blomberg SP, Webb CO (2010) Picante: R tools for integrating phylogenies and ecology. Bioinformatics 26:1463-1464. https://doi. org/10.1093/bioinformatics/btq166

Kunstler G, Falster D, Coomes DA, Hui F, Kooyman RM, Laughlin DC, Poorter L, Vanderwel M, Vieilledent G, Wright SJ, Aiba M, Baraloto C, Caspersen J, Cornelissen JHC, Gourlet-Fleury S, Hanewinkel M, Herault B, Kattge J, Kurokawa H, Onoda Y, Peñuelas J, Poorter H, Uriarte M, Richardson S, Ruiz-Benito P, Sun IF, Ståhl G, Swenson NG, Thompson J, Westerlund B, Wirth C, Zavala MA, Zeng H, Zimmerman JK, Zimmermann NE, Westoby M (2015) Plant functional traits have globally consistent effects on competition. Nature 529:204-207. https://doi.org/10. 1038/nature16476

Laliberte E, Legendre P (2010) A distance-based framework for measuring functional diversity from multiple traits. Ecology 91:299-305. https://doi.org/10.1890/08-2244.1

Lei L, Kong D, Li X, Zhou Z, Li G (2016) Plant functional traits, functional diversity, and ecosystem functioning: current knowledge and perspectives. Biodivers Sci 24:922-931. https://doi.org/10.17520/ biods. 2015295

Li S, Su J, Lang X, Liu W, Ou G (2018) Positive relationship between species richness and aboveground biomass across forest strata in a primary Pinus kesiya forest. Sci Rep 8:2227. https://doi.org/10. 1038/s41598-018-20165-y

Liang J, Crowther TW, Picard N, Wiser S, Zhou M, Alberti G, Schulze ED, McGuire AD, Bozzato F, Pretzsch H, de-Miguel S, Paquette A, Herault B, Scherer-Lorenzen M, Barrett CB, Glick HB, Hengeveld GM, Nabuurs GJ, Pfautsch S, Viana H, Vibrans AC, Ammer C, Schall P, Verbyla D, Tchebakova N, Fischer M, Watson JV, Chen HYH, Lei X, Schelhaas MJ, Lu H, Gianelle D, Parfenova EI, Salas C, Lee E, Lee B, Kim HS, Bruelheide H, Coomes DA, Piotto D, Sunderland T, Schmid B, Gourlet-Fleury S, Sonke B, Tavani R, Zhu J, Brandl S, Vayreda J, Kitahara F, Searle EB, Neldner VJ, Ngugi MR, Baraloto C, Frizzera L, Ba azy R, Oleksyn J, Zawi a-Nied wiecki T, Bouriaud O, Bussotti F, Finer L, Jaroszewicz B, Jucker T, Valladares F, Jagodzinski AM, Peri PL, Gonmadje C, Marthy W, OBrien T, Martin EH, Marshall AR, Rovero F, Bitariho R, Niklaus PA, Alvarez-Loayza P, Chamuya N, Valencia R, Mortier F, Wortel V, Engone-Obiang NL, Ferreira LV, Odeke DE, Vasquez RM, Lewis SL, Reich PB (2016) Positive biodiversity-productivity relationship predominant in global forests. Science 354:aaf8957. https://doi.org/ 10.1126/science.aaf8957

Liu J, Zhang X, Song F, Zhou S, Cadotte MW, Bradshaw CJA (2015) Explaining maximum variation in productivity requires phylogenetic diversity and single functional traits. Ecology 96:176-183. https:// doi.org/10.1890/14-1034.1

Liu X, Swenson NG, Lin D, Mi X, Umana MN, Schmid B, Ma K (2016) Linking individual-level functional traits to tree growth in a subtropical forest. Ecology 97:2396-2405. https://doi.org/10.1002/ecy. 1445

Loreau M (2000) Biodiversity and ecosystem functioning: recent theoretical advances. Oikos 91:3-17. https://doi.org/10.1034/j.1600-0706. 2000.910101.x

Madrigal-González J, Ruiz-Benito P, Ratcliffe S, Calatayud J, Kändler G, Lehtonen A, Dahlgren J, Wirth C, Zavala MA (2016a) Complementarity effects on tree growth are contingent on tree size and climatic conditions across. Europe. Sci Rep 6:32233. https://doi. org $/ 10.1038 /$ srep32233

Madrigal-González J et al (2016b) Complementarity effects on tree growth are contingent on tree size and climatic conditions across. Eur Sci Rep 6 
Marcoulides KM, Yuan K-H (2017) New ways to evaluate goodness of fit: a note on using equivalence testing to assess structural equation models. Struct Equ Modeling 24:148-153

Mason NW, de Bello F, Doležal J, Lepš J (2011) Niche overlap reveals the effects of competition, disturbance and contrasting assembly processes in experimental grassland communities. J Ecol 99:788-796

Mason NW, Pipenbaher N, Škornik S, Kaligarič M (2013) Does complementarity in leaf phenology and inclination promote co-existence in a species-rich meadow? Evidence from functional groups. J Veg Sci 24:94-100

McDonald RP, Ho M-HR (2002) Principles and practice in reporting structural equation analyses. Psychol Methods 7:64-82. https://doi. org/10.1037//1082-989x.7.1.64

Nilsson MC, Wardle DA (2005) Understory vegetation as a forest ecosystem driver: evidence from the northern Swedish boreal forest. Front Ecol Environ 3:421-428. https://doi.org/10.2307/3868658

Paquette A, Messier C (2011) The effect of biodiversity on tree productivity: from temperate to boreal forests. Glob Ecol Biogeogr 20:170 180. https://doi.org/10.1111/j.1466-8238.2010.00592.x

Petchey OL, Gaston KJ (2002) Functional diversity (FD), species richness and community composition. Ecol Lett 5:402-411

Poorter L, van der Sande MT, Thompson J, Arets EJMM, Alarcón A, Álvarez-Sánchez J, Ascarrunz N, Balvanera P, Barajas-Guzmán G, Boit A, Bongers F, Carvalho FA, Casanoves F, Cornejo-Tenorio G, Costa FRC, de Castilho CV, Duivenvoorden JF, Dutrieux LP, Enquist BJ, Fernández-Méndez F, Finegan B, Gormley LHL, Healey JR, Hoosbeek MR, Ibarra-Manríquez G, Junqueira AB, Levis C, Licona JC, Lisboa LS, Magnusson WE, Martínez-Ramos M, Martínez-Yrizar A, Martorano LG, Maskell LC, Mazzei L, Meave JA, Mora F, Muñoz R, Nytch C, Pansonato MP, Parr TW, Paz H, Pérez-García EA, Rentería LY, Rodríguez-Velazquez J, Rozendaal DMA, Ruschel AR, Sakschewski B, Salgado-Negret B, Schietti J, Simões M, Sinclair FL, Souza PF, Souza FC, Stropp J, ter Steege H, Swenson NG, Thonicke K, Toledo M, Uriarte M, van der Hout P, Walker P, Zamora N, Peña-Claros M (2015) Diversity enhances carbon storage in tropical forests. Glob Ecol Biogeogr 24: 1314-1328. https://doi.org/10.1111/geb.12364

Roberts J, Osvaldo MRC, De Aguiar LF (1990) Stomatal and boundarylayer Conductances in an Amazonian terra Firme rain Forest. J Appl Ecol 27:336-353. https://doi.org/10.2307/2403590

Szwagrzyk J, Gazda A (2007) Above-ground standing biomass and tree species diversity in natural stands of Central Europe. J Veg Sci 18: 555-562. https://doi.org/10.1658/1100-9233(2007)18[555: ASBATS]2.0.CO;2

Taylor AR, Seedre M, Brassard BW, Chen HYH (2014) Decline in net ecosystem productivity following canopy transition to latesuccession forests. Ecosystems 17:778-791. https://doi.org/10. 1007/s10021-014-9759-3

The R Core Team (2016) Changes in R: From version 3.3.1 patched to version 3.3.2 patched. The R Journal 8(2):511-514

Venail P, Gross K, Oakley TH, Narwani A, Allan E, Flombaum P, Isbell F, Joshi J, Reich PB, Tilman D, van Ruijven J, Cardinale BJ (2015)
Species richness, but not phylogenetic diversity, influences community biomass production and temporal stability in a re-examination of 16 grassland biodiversity studies. Funct Ecol 29:615-626. https:// doi.org/10.1111/1365-2435.12432

Villeger S, Mason NWH, Mouillot D (2008) New multidimensional functional diversity indices for a multifaceted framework in functional ecology. Ecology 89:2290-2301. https://doi.org/10.1890/07-1206.1

Wang J, Cheng Y, Zhang C, Zhao Y, Zhao X, Von Gadow K (2016) Relationships between tree biomass productivity and local species diversity. Ecosphere 7. https://doi.org/10.1002/ecs2.1562

Webb CO, Donoghue MJ (2005) Phylomatic: tree assembly for applied phylogenetics. Mol Ecol Notes 5:181-183. https://doi.org/10.1111/j. 1471-8286.2004.00829.x

Webb CO, Ackerly DD, Kembel SW (2008) Phylocom: software for the analysis of phylogenetic community structure and trait evolution. Bioinformatics 24:2098-2100. https://doi.org/10.1093/ bioinformatics/btn358

Wright IJ, Reich PB, Westoby M, Ackerly DD, Baruch Z, Bongers F, Cavender-Bares J, Chapin T, Cornelissen JHC, Diemer M, Flexas J, Garnier E, Groom PK, Gulias J, Hikosaka K, Lamont BB, Lee T, Lee W, Lusk C, Midgley JJ, Navas ML, Niinemets Ü, Oleksyn J, Osada N, Poorter H, Poot P, Prior L, Pyankov VI, Roumet C, Thomas SC, Tjoelker MG, Veneklaas EJ, Villar R (2004) The worldwide leaf economics spectrum. Nature 428:821-827. https:// doi.org/10.1038/nature02403

Wright SJ, Kitajima K, Kraft NJB, Reich PB, Wright IJ, Bunker DE, Condit R, Dalling JW, Davies SJ, Díaz S, Engelbrecht BMJ, Harms KE, Hubbell SP, Marks CO, Ruiz-Jaen MC, Salvador CM, Zanne AE (2010) Functional traits and the growth-mortality tradeoff in tropical trees. Ecology 91:3664-3674. https://doi.org/10. 1890/09-2335.1

Yuan Z, Wang S, Gazol A, Mellard J, Lin F, Ye J, Hao Z, Wang X, Loreau M (2016) Multiple metrics of diversity have different effects on temperate forest functioning over succession. Oecologia 182: 1175-1185. https://doi.org/10.1007/s00442-016-3737-8

Zhang Y, Chen HYH, Reich PB (2012) Forest productivity increases with evenness, species richness and trait variation: a global meta-analysis. J Ecol 100:742-749. https://doi.org/10.1111/j.1365-2745.2011. 01944.x

Zhang Y, Chen HYH, Taylor AR (2016) Aboveground biomass of understorey vegetation has a negligible or negative association with overstorey tree species diversity in natural forests. Glob Ecol Biogeogr 25:141-150. https://doi.org/10.1111/geb.12392

Zhang Y, Chen HYH, Taylor AR, Ostertag R (2017) Positive species diversity and above-ground biomass relationships are ubiquitous across forest strata despite interference from overstorey trees. Funct Ecol 31:419-426. https://doi.org/10.1111/1365-2435.12699

Publisher's note Springer Nature remains neutral with regard to jurisdictional claims in published maps and institutional affiliations. 